\title{
DISTANT LOVE BY ULRICH BECK AND ELISABETH BECK-GERNSHEIM (2013, CAMBRIDGE, POLITY PRESS)
}

\author{
Márta Radól, Dóra Bari, Gergely Horzsa, Bálint Duráczky and Katalin Fehér
}

The authors of Distant Love are Ulrich Beck and Elisabeth Beck-Gernsheim. The late Ulrich Beck was Emeritus Professor at the University of Munich, well-known for his book Risk Society ${ }^{2}$. Elisabeth Beck-Gernsheim is Visiting Professor at the University of Trondheim. In the book Distant Love ${ }^{3}$ Beck and Beck continue the work they started in the Normal Chaos of Love ${ }^{4}$ by arguing that the 'classic' family has begun to give away to a multiplicity of new types of family. Normal Chaos of Love showed how single-parent families and patchwork families emerged due to successive marriages and divorces. Distant Love also focuses on a new type of family by incorporating the global picture and introducing the concept of world families. In Beck and Beck's own words, the aim of the book is to "focus on the globalization of love". The content of the book does not rely on the authors' own research or empirical findings but illustrates its points using numerous examples from other studies.

The book employs diagnostic theory. In other words, it adopts the approach that a social phenomenon needs to be described first, and only after this can the reasons for it be observed. Consequently, the book is rather descriptive than explanatory. Moreover, the evolution of the culture of love follows the process of modernization. From the nation-state paradigm we move forward to the universalist model that came along with the development of European modernity from which emerged the conflict between freedom, equality and love, leaving behind the model of 'one household, one nationality, one identity'. The universality of the European model discussed in Normal Chaos of Love is, however, rethought and supplemented in this new book. The recent dominance of global capitalism and reflexive modernity have ushered in a (Western) cosmopolitan culture that is derived and interwoven from different areas of the globe and creates conflict within families.

\footnotetext{
1 The authors are Ph.D. students at the Corvinus University of Budapest. The corresponding author works for MTA TK "Recens"; email: marta.rado@stud.uni-corvinus.hu

2 Beck, U. (1992) Risk Society: Towards a New Modernity. New Delhi: Sage

3 Beck, U. and E. Ulrich (2013) Distant Love. Cambridge: Polity Press,

4 Beck, U. and E. Ulrich (1995): The normal chaos of love. Cambridge: Polity Press,
} 
The first chapter of the book is dedicated to defining the concept of world families. It provides the following definition: "lasting relationship with the »other « culture of origin' $[. .$.$] actively [\ldots]$ maintained across national frontiers or continents"s. The authors distinguish between two types of world families. The first one is the (1) 'multilocal world family' which refers to couples or families that remain together despite the individuals living in different countries. For example, they describe the global care chain in which non-Western women leave their families behind and move to Western countries to replace gainfully employed women in households. The second type refers to (2) couples or families who live in the same country but originally come from a different country, and, consequently, who have different concepts of the family. For instance, a German man may marry a Turkish immigrant. The authors stress that this concept is not clear-cut. The terms 'world family' and 'one-nation family' are only ideal types and some families cannot be assigned to one category exclusively.

The authors define the world family model along five dimensions: (1) distant other in the family, (2) cross-border communication, (3) global inequalities, (4) conflicting legal systems, and (5) clashing ideals in families. These focal areas create the structure for the whole book since each chapter details one of these dimensions. The following parts of this review describe each dimension.

First is the distant other in the family, wherein confrontation in the world is presented through the sphere of socialization and identity formation. In this way, intimate relations and fragments of the world are linked together. This topic is illustrated in Chapter 3 and 6 of the book.

The authors describe the process of geographical rescaling that is occurring due to global capitalism which affects the formation of relationships and intimacy. While distant love comes with new challenges compared to close love, cultural distance leads to the definition of new meanings and conflicts in the family. Cultural understandings and unspoken rules behind marriage, sexuality, and intimate relations differ across the world as they represent traditional hierarchies and habits. Families and couples that come from different cultural backgrounds are open to defining their own forms of intimacy. Marriage, love, and happiness and their interconnections have been given different, continuously changing meanings, as the book illustrates using models from premodern times, the fifties and the beginning of the 21st century. Various types of relationship now coexist, and, in view of the cultural and geographical distance of the individuals involved, they produce new, hybrid family models.

They highlight this fact using the example of mothers on the move - or more specifically, of female migrants who work as housemaids, nannies or babysitters in Western countries. Beck and Beck argue that, after barriers are raised in the West to immigration (mostly for industrial workers), a new form of economic migration

5 Beck, U. and E. Ulrich (2013) Distant Love, Cambridge: Polity Press, 43 pp. 
occurs in which female rather than male workers from less developed countries arrive in search of jobs. Domestic caretaking is usually the target occupation for these workers. This creates a transnational motherhood chain, resulting in the internationalization of caretaking that reshapes mother-child emotional relationships in both sending and receiving countries (e.g. 'global heart transplant').

Second, families engage in cross-border communication, which brings with it the potential for misunderstanding. In the absence of shared assumptions, world families must create their own procedures through reflexive negotiation. In this sense, these families strengthen interculturalism.

Chapter 2 focuses on the second dimension and analyzes the communication traps that happen to those families whose members live in the same place but come from different countries. The authors debate whether 'mixed relationships' differ from 'one-nation' couples. "On the one hand, they all insist that they are nothing out of the ordinary; on the other hand, their experience tells them that they are in

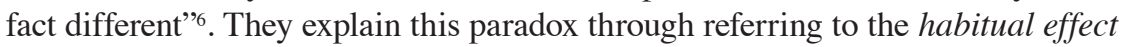
which says that people tend to regard their lives as normal; in other words, they say "leave us in peace, we belong together whether you like it or not" ". However, the authors claim that there are reasonable differences between one-nation couples and mixed couples. After this conclusion, the authors illustrate these differences by providing examples of how food-related misunderstandings, amongst other things, can cause fights. These examples demonstrate that more tradition-bound and intimate areas of life are extremely sensitive and exposed to new relations. Finally, Beck and Beck show that even in longstanding, stable relationships cultural differences can arise when either of the members suddenly rediscovers his or her roots. Accordingly, they stress the point that the life cycles of mixed families should be observed in order to understand all the conflicts which can arise from different cultural backgrounds.

Chapter 7 also touches upon the cross-border family situation through several examples that show how communication can be a challenge for family members. When someone from a Western (or Northern) country is married to someone from the East (or the South), the migrant encounters new cultural forms and hierarchies within the family which can be identified as communication-related problems. Nevertheless, the relationships between migrants and their families in their home countries change as well because of changes in the roles of the person who leaves. For instance, moving from East to West, in the case of women, increases the importance of family hierarchy. Therefore the participation of migrants in family life should be analyzed from the perspective of both the sending and receiving country.

6 Beck, U. and E. Ulrich (2013) Distant Love, Cambridge: Polity Press, pp 75.

7 Beck, U. and E. Ulrich (2013) Distant Love, Cambridge: Polity Press, pp 76. 
Third, global inequalities are embodied in world families. Family members occupy different positions in social hierarchies, and privileges and disadvantages appear not only externally (in society) but within families.

In connection with global inequalities, it is discussed that many mothers are now engaged in semi-legal or illegal occupations such as being maids for Western families, thus allowing local women to build their careers instead of doing housework and taking care of children. Beck and Beck say that global inequalities appear "in the kitchen"; in other words, in domestic surroundings in the households of the West. The differences for both parties can be culturally hard to overcome. The authors argue that, despite the fact that employee-employer relationships are often seen as being mutually beneficial, the benefits and drawbacks are typically unevenly distributed.

Fourth, world families are stuck between conflicting legal systems. This introduces new features and consequences for marriages and divorces, as well as immigration.

Chapter 9 highlights several problems with the legal system concerning new technological interventions in fertility that are as yet unsolved. Questions are being raised about the rights of increasing numbers of children born through technologically assisted forms of conception (concerning, for example, sperm donors, egg donors and surrogate mothers). The authors emphasize that if children do not have the chance to obtain information about their biological parents, the next generation might not be interested in their origins. This could change the meaning of the 'family' in the near future.

The problem of conflicting legal systems is also discussed in Chapter 6. Since restrictive laws were introduced in Western countries to avoid mass flows of immigrants, migrant workers (mostly female domestic workers) have been forced to "live in the shadows". Their semi-legal or illegal status means they must work harder, and for less money. With the appearance of greater numbers of female domestic workers, a silent conspiracy is at work within Western families. As gender equality with housework is not at all guaranteed, equilibrium between wife and husband can be maintained and a woman's career can be built on the employment of maids who act to "stabilize the state of peace between sexes". However, the situation is highly gender-unbalanced at the global scale and also contributes to the maintenance of a welfare society at the national level.

Fifth, world families inherently involve the clashing ideals of families in terms of whether relations should be based on equality or patriarchy, how to bring up children, ideas about marriage, etc.

Chapter 5 deals with cross-border marriage as the potential key to a better life for women. The globalization of capital, labor, and information has made possible migration for marriage. Today, the number of such marriages is increasing; a fact

8 Beck, U. and E. Ulrich (2013) Distant Love, Cambridge: Polity Press , 284 pp.

CORVINUS JOURNAL OF SOCIOLOGY AND SOCIAL POLICY 1 (2016) 
which has attracted both political and media interest. In this chapter the authors attempt to answer three important questions: (1) why do people from two different "worlds" choose to connect their lives? (2) how do these two "worlds" unite after marriage, and, (3) why do individuals have such negative opinions about migrant marriages? What are the myths and what is the reality?

The authors (in Chapter 8 and 11) argue that, even though migrants are sometimes thought to come from traditional cultures, world families are rather modern (i.e. post-modern) inventions. World-family members are part of small social groups with multiple cultures and do not forget their origins or values (including whatever concepts they hold about families), but instead build up their own cosmopolitan values, in which different cultures exist in parallel. 'Traditional families' are loyal to the family and the state in which they live, but the first loyalty of world families towards the family is not paralleled with their loyalty towards the state because they, as a community, do not belong to a state - a fact which leads to important legal issues: transactions within world families cannot legally controlled by any state.

The five dimensions which describe the peculiarities of a world family are not only important as concerns the functioning of marriage, but play a decisive role even before marriage occurs. The conditions (laws) of the host country are very important in terms of how individuals choose their marriage-based migration strategy. Beck and Beck mention two key ways: either individuals choose a country to which everyone can migrate, or they choose a country to which only certain groups can migrate under certain conditions. From the point of view of migration it is important to find a spouse who will support the migration of the family members of the receiving country. This is because so many marriages are undertaken with a view to later assisting in the migration process of wider populations of underdeveloped countries. Unfortunately, numerous cultural differences can generate conflicts in marriage that cause women to become victims or, in extreme cases, perpetrators of harm. According to the authors, because of increasing inequality and changes in the global labor market, the number of migration-related marriages are increasing - so there is a need for a change in the political climate surrounding this topic.

At the end of the book, the authors describe a vision of the future. They argue that world families, bound together by strong relationships between people of different origins and cultures, will gradually build a global society in which cultural conflicts will gradually decrease and the problem of long-distance personal relationships will gradually decline in importance from a cultural perspective.

The concept of the world family collects together many different life situations in one single platform. While changes in the intimate spheres of families are ubiquitous due to cultural and geographical distance, they have different effects in the light of changes in global capitalism. These effects are especially important in relation to traditional and new gender roles in families and in relation to the labor 
market. Examples illustrate how the global flux of domestic workers contributes to empowering Western women on the labor market, while men are still not getting more involved in doing housework and caring work. The topic of women's migration for marriage and for work is also brought to the surface. Immigrant domestic is changing in parallel with that of Western women as it is they who typically provide for their families at a distance. Distant love opens up the research towards a systematic gender-related understating of world families.

The authors claim that the globalization of love is a new phenomenon, thus the concept of world families should be introduced into the sociology of the family. However, numerous authors have already argued that globalization is not a new phenomenon but only part of a historical process. Scholte ${ }^{9}$ has categorized such researchers into three groups based on how they deal with globalization: (1) they consider it to be a new phenomenon, (2) they consider it to be part of a historical process which is a component of a cyclical trend, or (3) they consider it to be part of a linear historical process. The last two groups agree that globalization is not a new phenomenon and that it has antecedents. Taking into account this perspective, the globalization of love should thus not be considered a new phenomenon since the roots of world families can be found in the past. LAT (living apart together) families can be considered the forerunners of multi-local world families ${ }^{10}$. LAT families in which one member lives apart due to constraints are similar to Beck and Beck's multi-local families ${ }^{11}$. Also, families in which heterogeneous marriage (e.g. which involve marrying into a different class or religion) display similar features to families which are located in the same country but whose members come from different countries ${ }^{12}$. Accordingly, this review argues that the globalization of love is not a brand new concept, but that it is embedded in history. Consequently, instead of introducing new concepts, pre-existing concepts may be refreshed to describe this phenomenon.

9 Scholte, J. A. (2000) Globalization: A Critical Introduction, New York, Macmillan

10 Hoffmann-Nowotny, H-J. (1995) Die Zukunft der Familie - die Familie der Zukunft In Gerhard, U. - Hradil, S.:Familie der Zukunft. Leske\&Budrich, Opladen, pp. 325- 348

11 Beaujouan, E.,Régnier-Loilier, A.and C. Villeneuve-Gokalp (2009), "Ni seuls, ni en couple. Étude des relations amoureusesstables non cohabitantes“ In Arnaud Régnier-Loilier (eds.): Portraits de familles, l'enquête Etude des relations familiales et intergénérationnelles. Paris: Les cahiers de l'Ined, pp. 87-112

12 Horwitz S. and P. Lewin (2007), "Heterogeneous human capital, uncertainty, and the structure of plans: A market process approach to marriage and divorce“, Springer Science + Business Media 